\title{
MANAGING URBAN SPRAWL USING REMOTE SENSING AND GIS
}

\author{
Krishnaveni K.S. ${ }^{1}$, Anilkumar P.P. ${ }^{2}$ \\ ${ }^{1}$ Research Scholar, Department of Architecture \& Planning, NIT Calicut, Kerala, India - kveni07@gmail.com \\ ${ }^{2}$ Department of Architecture \& Planning, NIT Calicut, Kerala, India - ppa@ nitc.ac.in
}

KEYWORDS: Urban sprawl, remote sensing, GIS, built-up index, Shannon's entropy, sustainability

\begin{abstract}
:
Indian cities, like several other developing cities around the world, are urbanizing at an alarming rate. This unprecedented and uncontrolled urbanization may result in urban sprawl, which is characterized by low-density impervious surfaces, often clumsy, extends along the fringes of metropolitan areas with unbelievable pace, disperse, auto-dependent with environmentally and socially impacting characteristics. The ill-effects of urban sprawl in developing countries scenario is a bit complicated compared to that of developed countries because of uncontrolled population growth and haphazard urbanization. This paper attempts to investigate the capabilities of remote sensing and GIS techniques in understanding the urban sprawl phenomenon in a better way compared to timeconsuming conventional methods. An overview of the enormous potential of remote sensing and GIS techniques in mapping and monitoring the Spatio-temporal patterns urban sprawl is dealt with here. The spatial pattern and dynamics of the urban sprawl of Kozhikode Metropolitan Area (KMA, Kerala, India) during the period from 1991 to 2018 using the integrated approach of remote sensing and GIS are attempted here. Index derived Built-up Index (IDBI) which is a thematic index-based index (combination of Normalized Difference Built-up Index (NDBI), Modified Normalized Difference Water Index (MNDWI) and Soil Adjusted Vegetation Index (SAVI)) is used for the rapid and automated extraction of built-up features from the time series satellite imageries. The extracted built-up areas of each year are then used for Shannon's entropy calculations, which is a method for the quantification of urban sprawl. The results of IDBI and Shannon's entropy analysis highlight the fact that there occurs an alarming increase in the built-up areal extent from 1991 to 2018. The urban planning authorities can make use of these techniques of built-up area extraction and urban sprawl analysis for effective city planning and sprawl control.
\end{abstract}

\section{INTRODUCTION}

The 2019 review of the World Population Prospects by the United Nations Population Division sets out that by the year 2030, the World's urban population will increase to 4.9 billion, whereas the World's rural population is projected to reduce by some 28 million between 2005 and 2030. Indeed, by 2050, very few nations are anticipated to have higher rural shares than urban ones. More than half of the world's population currently lives in metropolitan regions and is projected to reach twothirds by 2050. (Web-1). Therefore, at a global scale, al potential population rises will be focused more in towns and cities, majority of them will be in developing countries. This massive increase in the urban population, together with an unprecedented rate of urbanization, may cause unplanned, uncontrolled or unrestricted growth/spreading of urban areas into the peripheries may be recognized as urban sprawl.

The notion of urban sprawl has been interpreted and defined in countless ways, and as a consequence, there has been no agreement on the definition of urban sprawl. However, a widely accepted definition is uncontrolled, unlawful, unplanned, and uncoordinated low-density single-use development facilitates that does not provide for a functional and appealing combination of land use mixes and/or is not functionally connected to neighboring land-uses and which variously appears as leapfrog, or isolated development, ribbon or strip with scattered residential neighbourhoods and commercial strip development, with automobile dominance which are aesthetically displeasing in nature (Nelson, 1995,Hiller, 2013). There is an enormous number of journals and publications that explore the adverse effects of urban sprawl on metropolises. Freilich (1999) identified seven adverse sprawl effects, including impacts on society, impacts on housing, impacts on jobs, fiscal impacts, political impacts, impacts on transport, impacts on agriculture, and open space.

It is imperative to discover the appropriate methods to analyze the spatial features, and unique mechanism of urban sprawl within the Indian context as the consequences of urban sprawl in India are on the rise. The measurement, mapping, and tracking of urban sprawl are essential for public authorities and planners in any region to accomplish adequate management of urban sprawling. The process of urban sprawl measurement has been a hot topic of research among the academic fraternity. In this context, remote sensing and geographical information system (GIS) methods are outlined in this study to monitor and evaluate urban sprawl. To monitor dynamic changes in urban sprawl, the built-up regions were extracted from Landsat classified images of four distinct periods. Across the world, researchers are focusing on various multi-dimensional indicators of urban sprawl by employing remote sensing and GIS-based analysis or descriptive statistical analysis. (Ewing et al., 2002) (Frenkel, M. A. 2005) (Galster, G. et al. 2001) (Barnes et al. 2001) (Song et al. 2004). This study attempts to find an easy way to extract the built-up features using an index derived built-up index through the techniques of remote sensing and GIS.

Among the various indicators of urban sprawl, this study considers the built-up features as an indicator of urban sprawl and attempted to map all the built-up features within the study area using a completely automated method of built-up extraction known as Index-derived built-up index (IDBI) which was proposed by $\mathrm{Xu}$ in 2008 . The three thematic indices used 
for the generation of IDBI are the Soil Adjusted Vegetation Index (SAVI, the Normalized Difference Water Index (NDBI), and the Modified Normalized Difference Water Index (MNDWI). IDBI helps to extract built-up features very quickly by effectively eliminating background noise caused by water, soil, etc.

\section{URBAN SPRAWL: CAUSES AND CONSEQUENCES}

Although there are various measures and dimensions for the phenomenon of urban sprawl, there is no common universally accepted definition for the process of urban sprawl. It should always be better to describe rather than to define the concept of urban sprawl. (Galster et al. 2000, Wilson et al.). Generally, urban sprawl is characterized by an example of a sprawling city like Los Angeles which symbolizes sprawl characteristics or as an aesthetic condition or as the cause of an unwanted externality or as selected patterns of land use/ land development or even defined as a process of development over time and space (Galster, 2010). A widely accepted definition of urban sprawl is low-density, dispersed, decentralized, polycentric sub-urban development, which is mainly catalyzed by low-cost auto travel and technological innovations (Ewing, 1997). The notable characteristics of urban sprawl are discontinuous development with low-density residential patterns, fragmentation of land uses, transportation dominated by private vehicles, excessive land consumption, and social segregation with aesthetically displeasing type of development. Based on its spatial form, sprawl can be classified as linear strip tribbon development (occur as a result of rail/road development), leapfrog development, single-use development, and continuous lowdensity sprawl and single-use development. (Batty et al., 2003).

There are a large number of factors that add fuel to the process of urban sprawl. They are urban expansion coupled with population growth, rural-urban migration, economic growth, industrialization, lower land value in the peripheries, lower tax rates in the fringes, lack of affordable housing at the city core, physical geography, emergence of Information and Communication Systems (ICT) and other technological innovations, desire for living in greener surroundings, lack of spatial planning and failure to enforce planning etc. These causative factors vary from place to place. In a developed country, people see sprawl as a choice, whereas in a developing country, sprawl is mainly seen as a result of necessity (Kew, 2013).

The damaging dimensions of urban sprawl are very much critical, and it is inevitable to tame it for the sustainability of our environment. Urban sprawl consequences can be broadly categorized into three groups; social/community impacts, economic impacts, and environmental/ecological impacts. Table 1 summarizes the detrimental impacts arising from uncontrolled urban sprawl. The measurement, mapping, and surveillance of the extent of urban sprawl are exceptionally crucial for government officials and planners in any region to manage the undesired effects resulting from urban expansions.

Table 1: Impacts of uncontrolled Urban Sprawl

\begin{tabular}{|l|l|l|}
\hline $\begin{array}{l}\text { Community } \\
\text { Impacts }\end{array}$ & Economic Impacts & $\begin{array}{l}\text { Ecological } \\
\text { Impacts }\end{array}$ \\
\hline
\end{tabular}

\begin{tabular}{|c|c|c|}
\hline $\begin{array}{l}\text { 1. Segregated } \\
\text { residential } \\
\text { development } \\
\text { 2. An overall } \\
\text { reduction in } \\
\text { quality of life } \\
\text { 3.Less social } \\
\text { interactions \& } \\
\text { more prolonged } \\
\text { time to commute } \\
\text { 4.A large } \\
\text { proportion of single } \\
\text { households with } \\
\text { intensive resources } \\
\text { utilization } \\
\text { 5.Increased health } \\
\text { issues (Eg. Asthma } \\
\text { because of air } \\
\text { pollution, Insomnia } \\
\text { and other health } \\
\text { effects because of } \\
\text { noise pollution and } \\
\text { urban heat island } \\
\text { effect) } \\
\text { 6.Increased obesity, } \\
\text { stress and physical } \\
\text { activity } \\
\text { 7. spatial and } \\
\text { functional } \\
\text { demarcation of } \\
\text { areas where people } \\
\text { live, work, and } \\
\text { play/leisure. }\end{array}$ & $\begin{array}{l}\text { 1. Economic } \\
\text { discrimination } \\
2 \text {. Increase in } \\
\text { transportation cost } \\
\text { for commuting to } \\
\text { households } \\
\text { 3. Higher cost } \\
\text { because of traffic } \\
\text { congestion } \\
\text { 4.Higher energy } \\
\text { and land } \\
\text { consumption per } \\
\text { person } \\
\text { 5. A rise in public } \\
\text { service costs and } \\
\text { taxes } \\
\text { 6. Higher costs for } \\
\text { the substitution of } \\
\text { various ecosystem } \\
\text { related services } \\
\text { with technology } \\
\text { 7. Higher cost for } \\
\text { extending urban } \\
\text { infrastructure into } \\
\text { newly developed } \\
\text { areas }\end{array}$ & $\begin{array}{l}\text { 1. Heavy } \\
\text { dependence on } \\
\text { automobiles } \\
\text { resulted in higher } \\
\text { air pollution and } \\
\text { depletion of fossil } \\
\text { fuels. } \\
\text { 2. Water pollution } \\
\text { and hydrological } \\
\text { alterations of } \\
\text { watersheds, } \\
\text { surface } \\
\text { watercourses etc. } \\
\text { because of an } \\
\text { increase in } \\
\text { impervious } \\
\text { surfaces } \\
\text { 3.Higher noise } \\
\text { pollution } \\
\text { 4. Loss of arable } \\
\text { soil } \\
\text { 4.Disruption of } \\
\text { critical natural } \\
\text { habitats and } \\
\text { environmentally } \\
\text { sensitive areas like } \\
\text { wetlands, sacred } \\
\text { groves, wildlife } \\
\text { corridors, etc. } \\
\text { 5.Fragmentation } \\
\text { of landscape and } \\
\text { loss of existing } \\
\text { green } \\
\text { infrastructure } \\
\text { 6. Reduced } \\
\text { resilience of } \\
\text { ecosystem } \\
\text { 7.Loss of } \\
\text { agricultural land, } \\
\text { built heritage, } \\
\text { natural open } \\
\text { spaces, and loss of } \\
\text { recreational areas. } \\
\text { 8.Climate } \\
\text { alteration } \\
\text { 9. Reduces } \\
\text { landscape } \\
\text { attractiveness }\end{array}$ \\
\hline
\end{tabular}

\section{URBAN SPRAWL MANAGEMENT USING REMOTE} SENSING NAD GIS

In order to understand the rapid changes that are happening to our cities, mapping and monitoring of the urban evolution at spatial and temporal scales are inevitable. Uncontrolled urbanization, together with unprecedented population growth, results in detrimental land-use land-cover changes, which can be considered as a threat to urban sustainability. Remote sensing and GIS techniques are innovative tools widely used to track and monitor urban growth, changes in land use land cover features and urban transition. (Bhatta, 2012).

Remote sensing is the art and science of obtaining information about an object, an area or phenomenon, without direct contact 
with the object or target under consideration (Lillesand \& Keifer). The electromagnetic radiation is used as a critical information source in remote sensing. To study the properties of a target, the technique of remote sensing makes use of the energy that is emitted/ reflected/ absorbed by the destination under consideration. A Geographical Information System (GIS)is a "computer-based system that provides the following four sets of capabilities to handle georeferenced data: input, data management (storage and retrieval), manipulation and analysis, output" (Aronoff, 1989). GIS is composed of a set of tools for capturing, storing, retrieving, analyzing and displaying information which are spatially referenced to the earth. GIS offers forward mapping features like a database management system for displaying geographical information, as well as backward mapping functions for carrying out "querying." In addition to the quick data production capabilities, GIS technologies are an immense source of help for the policy implementers.

With the integrated use of remote sensing and GIS techniques, the urban sprawl phenomenon can be mapped effectively and monitored regularly. Recent advances in satellite remote sensing sensor capabilities help to create urban maps with even tiny details and help planners and policymakers to get a more indepth understanding of urban expansion, urban sprawl, and urban land management issues (NASA 2001). In the beginning, remote sensing was dominated by aerial photography. The first launch of the Landsat satellite in 1972 paved the way for satellite based remote sensing techniques. Later, the emergence of very high-resolution satellites paved the way for a vast array of urban applications with better results. Urban remote sensing with space-borne sensors is, in fact, an emerging area of research for the remote sensing community, urban planners, etc. Integrated remote sensing and GIS technologies can contribute much to the generation of digital maps with detailed data on urban growth and the evolution of urban sprawl of a city or region. The magnitude and level of urban sprawl, the various forms of sprawl and its existence, etc can be easily identified using advanced remote sensing and GIS techniques.

Remote sensing and GIS applications will be immensely beneficial to developing countries where there are restricted funding and little data on urban land characteristics and their modifications over time. With these techniques, developing countries can establish an urban spatial information system by integrating conventional data (hard copy maps and reports), ground measurements, and digital data (satellite images, digital maps, attribute data, etc.). The valuable information gained from remote sensing can contribute much in the domains of monitoring, quantifying, modeling and ultimately predicting the phenomenon of urban sprawl. The implications of combined remote sensing and GIS technologies are effective and timely tracking of urban sprawl along with a better understanding of various benefits applied in the areas of urban planning and management.

The extensive availability of freely downloadable satellite imageries and other spatial data, together with numerous userfriendly geospatial tools, resulted in a large number of applications relevant urban sprawl studies. Typical research of urban sprawl includes an effort to quantify the built-up features and quantity of paved surface in a region using remotely sensed information from satellite imageries. In general, the built-up area and the amount of paved surface are considered as indicators of urban sprawl. The changes that are happening to the built-up and paved features will be used as a proxy to quantify the nature and extent of urban sprawl. In other terms, the mapping and monitoring of urban sprawl using geospatial tools will enable us to visualize how and where the city is growing in an uncontrolled and unplanned manner. This will help the concerned local planning authorities to get an easy understanding of the development that can be sanctioned or need to be avoided in a particular region. Additionally, the identification and preservation of pristine natural environmental resources, natural open space, environmentally sensitive areas like wetlands, sacred grooves, etc. will help in the reduction of urban sprawl and thereby enhance urban sustainability.

The advantages of remote sensing applications in urban sprawl mapping and monitoring are listed below.

- $\quad$ Possibility of incorporating multiple sensor data with the same or different spatial, spectral or temporal resolutions.

- $\quad$ Extensive areal coverage and quick data acquisition

- Availability of temporal datasets/repetitive data acquisition

- $\quad$ Can process the data digitally and analyze it efficiently compared to conventional methods

- It can integrate with GIS/GNSS, database management systems, etc.

- Cost-effective

- Technologically sound

- It provides an accurate and permanent recording of spatial data and processes.

Despite the countless benefits of remote sensing and GIS applications in urban sprawl studies, there are some challenges/ limitations associated with it. Poor atmospheric conditions become a real hindrance to the data availability of cloud-free images of specific scenes and time period. High spatial resolution images are often costly, and there are chances for the occurrence of spectral variability within one class. In many cases, the shadows of trees and buildings pose a greater threat to classification accuracies by reducing the class separability. There will be spectral ambiguity arising from mixed pixels between urban land use and land covers such as bare soil and dry mud with impermeable surfaces, vegetation with forest, etc. The complexity and dynamics of the urban landscape is also a challenge for urban geospatial applications. It is a cumbersome task to integrate multi-source data especially in the case of temporal studies on urban dynamics. There are chances for errors while integrating satellite data with other supplementary data like census data. Besides, the presence of various built-up features in a small region results in the generalization of pixels, ultimately contributing to errors in classification. It is, therefore, necessary to create new strategies and further refine prevailing tools and techniques to take complete advantage of the enormous potential of remote sensing data in the urban setting.

\section{CASE STUDY: URBAN SPRAWL QUANTIFICATION USING REMOTE SENSING AND GIS}

The unprecedented population growth, together with uncontrolled urbanization, force the cities to expand further to accommodate the urban growth. The urban expansion towards the periphery is regarded as urban sprawl. An rise in the builtup features especially in the urban fringes can be considered as common characteristic feature of urban sprawl. The built-up area is a prospective and comparatively precise parameter for urban sprawl measurement. The dynamics of built-area change over the years give vital information regarding the nature, extent, and development of urban sprawl. In other words, urban sprawl is linked to the growth of built-up features within a region. In this study, a thematic index-based built-up index 
known as the index-derived built-up index (IDBI) is used to extract the built-up feature class quickly and efficiently. This index is composed of three indices viz., the Normalized Difference Built-Up Index (NDBI), the Soil Adjusted Vegetation Index (SAVI) and the Modified Normalized Difference Water Index (MNDWI). The objectives of the study are to extract the built-up areas and quantify its areal extend from 1991 to 2000 and 2018 using IDBI (Index derived built-up index) and to measure the degree of dispersion using Shannon's entropy. The detailed study of urban sprawl using IDBI is discussed with the built-up area changes from 1991 to 2018 in the subsequent sections.

\subsection{Study Area}

Kozhikode Urban Agglomeration (KUA) in Calicut district of Kerala state, India is chosen as the study area for smart growth suitability analysis using GIS. As it is composed of contiguous counties, it is better to take urban agglomeration as an appropriate unit of analysis. It includes Kozhikode City Corporation, Municipalities like Feroke, Koduvally, Payyoli, Koyilandy, Ramanattukara, and Vadakara, together with some census towns and outgrowths as per Census 2011. Figure 1 shows the map of the study area.

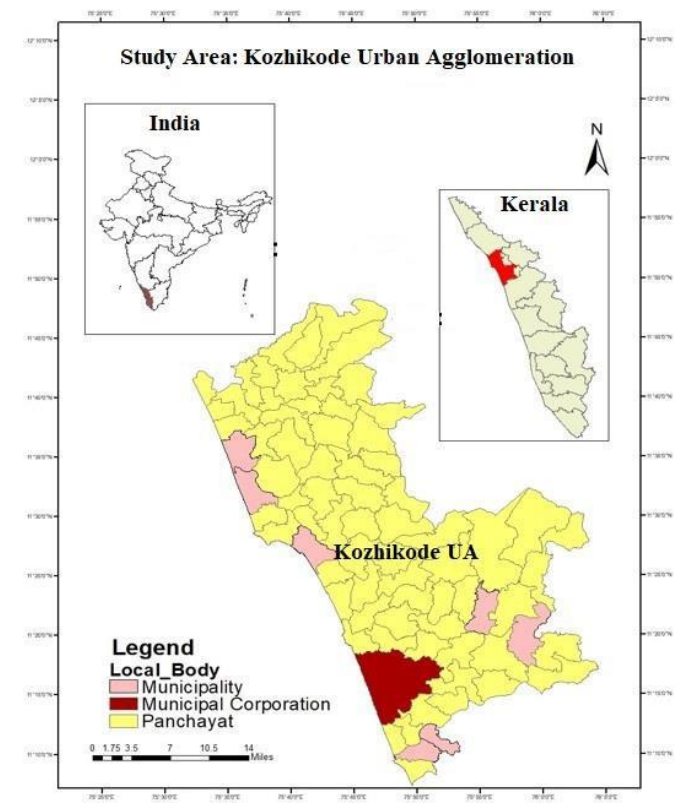

Figure 1: Map of Study Area

\subsection{Methodology}

\subsubsection{Data and pre-processing}

The satellite data used for this study were downloaded freely from the USGS Earth Explorer website(Web-2). Landsat temporal images of the years 1991, 2000 and 2018 were used for this study. Landsat Thematic Mapper (TM) of 1991, Landsat Enhanced Thematic Mapper (ETM+) of 2000, and Landsat 8 of 2018 were made use of. (Table 1). To minimize the errors from temporal variation, only the imageries of the same time period (February-March) were considered in this study. The downloaded imageries were in GeoTIFF format, and data were initially pre-processed and finally cropped to the extent of the study area (Figure 2). Erdas imagine software is used for all tasks related to image processing and index derivation, whereas mapping and display related works are carried out using ArcGIS. Besides, the Google earth application is also made use in this study for various applications related to accuracy assessment.
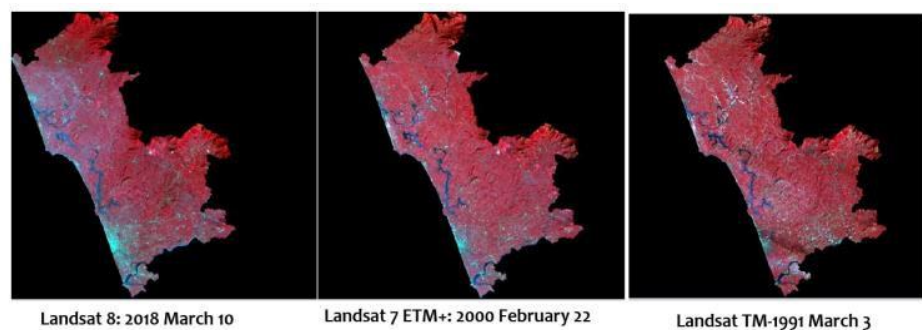

Figure 2: Landsat images of the study area for various years

Table 1. Details of Satellite imageries used

\begin{tabular}{|c|c|c|c|}
\hline Date & Sensor & Path/row & $\begin{array}{l}\text { Bands with } \\
\text { resolution } \\
\text { (in meters) }\end{array}$ \\
\hline $\begin{array}{l}1991 \text { March } \\
3\end{array}$ & $\begin{array}{l}\text { Landsat 5- } \\
\text { TM }\end{array}$ & $145 / 052$ & $\begin{array}{l}\text { Blue (30), } \\
\text { Green(30m), } \\
\text { Red (30), } \\
\text { NIR (30), } \\
\text { SWIR1(30), } \\
\text { TIR } \\
(120(30)), \\
\text { SWIR2(30) }\end{array}$ \\
\hline $\begin{array}{l}2000 \\
\text { February } 22\end{array}$ & $\begin{array}{ll}\text { Landsat } & 7 \\
\text { ETM+ } & \end{array}$ & $145 / 052$ & $\begin{array}{ll}\text { Blue } & (30), \\
\text { Green } & (30), \\
\text { Red } & (30), \\
\text { NIR } \quad(30), \\
\text { SWIR1(30), } \\
\text { TIR }(60(30)) \text {, } \\
\text { SWIR2(30), } \\
\text { PAN (15) }\end{array}$ \\
\hline $\begin{array}{l}2018 \text { March } \\
10\end{array}$ & Landsat 8 & $145 / 052$ & $\begin{array}{ll}\text { Coastal } \\
\text { aerosol } & (30), \\
\text { Blue } & (30), \\
\text { Green } & (30), \\
\text { Red } & (30), \\
\text { NIR } & (30), \\
\text { SWIR1(30), } & \text { SWIR2(30), } \\
\text { PAN (15), } & \text { Cirrus (30), } \\
\text { TIRS1(100), } & \text { TIRS-II } \\
(100) & \end{array}$ \\
\hline
\end{tabular}

\subsubsection{Automated built-up area extraction using Index} derived built-up index

The methodology adopted for the rapid extraction of built-areas areas from time series of Landsat satellite imageries is given in Figure 3. From the website of USGS Earth explorer satellite imageries of interest were freely downloaded. It includes Landsat 5-TM of 1991, Landsat 7 ETM+ OF 2000, and Landsat 8 of 2018. Then all these images were clipped/ subsetted by using the shapefile of Kozhikode Urban Agglomeration as input for the extent of the study area to be clipped. The data were 
initially pre-processed and rectified after subsetting it to the required areal extent of Kozhikode Urban Agglomeration.

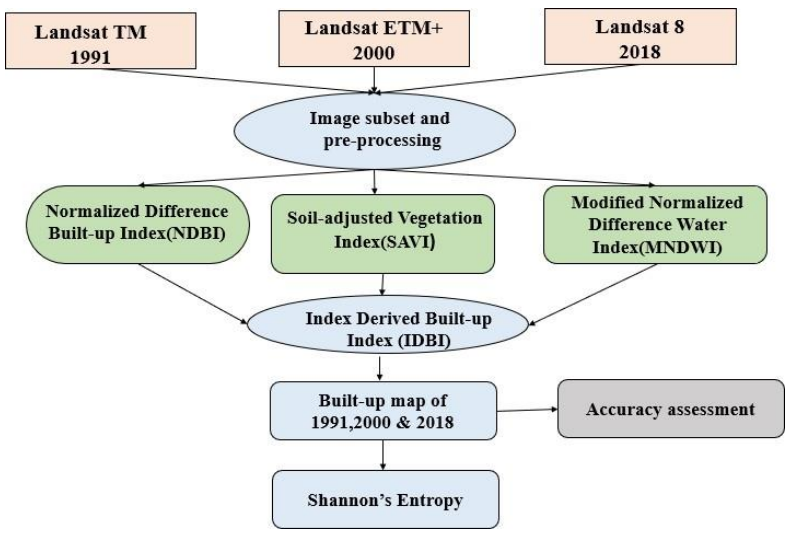

Figure 3: Flow chart of the methodology

a. Normalized Difference Built-up Index(NDBI)

$$
N D B I=\frac{M I R-N I R}{M I R+N I R}
$$

Proposed by Zha et al. (2003). In the Mid Infrared (MIR) region, an increased spectral reflectance is shown by the builtup features compared to the Near Infrared (NIR) region of the electromagnetic spectrum. There are chances for the mixing of vegetation noise with the built-up land information. In Landsat TM and ETM+, band 4 denotes NIR, and band 5 denotes MIR, whereas, in Landsat 8 , band5 and 6 denote NIR and MIR, respectively.

\section{b. Soil Adjusted Vegetation Index (SAVI)}

$$
S A V I=\frac{(N I R-R e d)(1+L)}{(N I R+\operatorname{Red}+L)}
$$

Where $\mathrm{L}$ is the soil adjustment factor (Normally value $=0.5$ ). In Landsat TM and ETM+, band 3 denotes Red, and band 4 denotes NIR, whereas, in Landsat 8 , band 4 and 5 denote Red and NIR, respectively. SAVI is preferred over NDVI because it is more sensitive in vegetation detection even in urban areas with less vegetation coverage. A study conducted by Ray (2006) on vegetation indices concluded that NDVI shows better performance of vegetation mapping in areas with plant cover $30 \%$ or more, whereas SAVI performed with better accuracies in areas with plant cover as low as $15 \%$. SAVI is adopted here because it is more suitable for an urban area.

c. Modified Normalized Difference Water Index (MNDWI)

$$
M N D W I=\frac{(\text { Green }-M I R)}{(\text { Green }+ \text { MIR })}
$$

Bands 2 and 5 denote Green and MIR respectively in Landsat TM and ETM+ imageries, whereas bands 3 and 6 denote Green and MIR in Landsat 8 Imagery. MNDWI is the modified version of the Normalized Difference Water Index (NDWI) developed by McFeeters in the year 1996. NDWI is obtained by substituting middle infrared (MIR) with near infra-red(NIR) band. MIR is more sensitive to water information compared to NIR, and hence MNDWI offers better performance in extracting water features compared to NDWI. It helps in the enhancement of open water features while effectively suppressing noises from built-up land, vegetation, and soil features.

\section{d. Index derived Built-up Index (IDBI)}

$I D B I=\frac{\left[N D B I-\frac{S A V I+M N D W I}{2}\right]}{\left[N D B I+\frac{S A V I+M N D W I}{2}\right]}$

IDBI is an index derived from three indices, namely, NDBI, MNDWI, and SAVI. In this index, the spectral clusters of the built-up, water body, and vegetation are well isolated, and there is a significant reduction in redundancy between original imagery and thematic band imageries. Its value ranges from -1 to +1 wherein, built-up features exhibit positive values, and suppressed vegetation or water noise should have zero to negative values. A notable feature of IDBI is that the image can be used as itself without geometric corrections for further computations.

\subsection{Results and Discussions}

\subsubsection{Built-up Area Extraction Using Index -based Built-up Index (IDBI)}

Here, an increase in built-up areas is considered as a proxy for the rise in urban sprawl. A thematic index-based index called Index Derived Built-up Index (IDBI) is used to perform the automatic extraction of the built-up classes from the landsat imageries of 1991, 2000 and 2018. The built-up features were displayed in a light grey to white colour in the IDBI image whereas the vegetation and water features were substantially obscured and outlined in dark grey to black shade. To extract the urban built-up classes of 1991, 2000, and 2018, threshold values that best discriminate built-up features were manually determined. In general, water and vegetation classes showed negative IDBI values whereas built-up features exhibited positive values. Pixels with values above the threshold value have been categorized as built-up land and given a value of 1 , whereas pixels with values less than or equal to the threshold are labelled as non-built up features and assigned a value equal to zero. The resulting image is, therefore, a binary image with value one as extracted built-up information and zero as other classes. Figure 4 shows the final map of built-up areas of 1991,2000 and 2018.
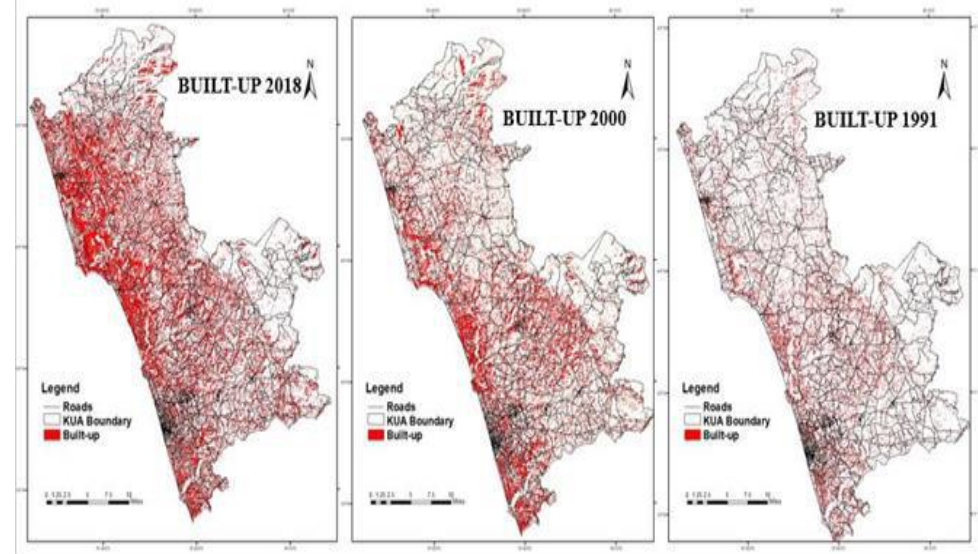

Figure 4: Built-up area map of 2018, 2000 and 1991 derived from IDBI 


\subsubsection{Accuracy Assessment}

For accuracy assessment, field data points were selected, and the spatial locations of these points were identified with the help of a handheld GPS. About 610 ground truth points were selected. About 310 points are selected for built-up features, and 300 points for non-built-up features were collected using handheld GPS. The ground sample points are overlaid on each of the maps to determine the classification accuracies. For this, all the built-up features raster maps were converted into a vector format. Then intersection is carried out between sample data points and all built-up maps. The accuracy assessment of builtup features derived from IDBI is shown in Table 2. The analysis shows that with a kappa coefficient of 0.812 , the overall accuracy is $90.65 \%$.

Table 2: Accuracy assessment of IDBI

\begin{tabular}{|l|l|l|l|l|}
\hline & $\begin{array}{l}\text { Built-up } \\
\text { land }\end{array}$ & $\begin{array}{l}\text { Non- } \\
\text { built-up } \\
\text { land }\end{array}$ & Total & $\begin{array}{l}\text { User's } \\
\text { accuracy }\end{array}$ \\
\hline $\begin{array}{l}\text { Built-up } \\
\text { land }\end{array}$ & 285 & 32 & 317 & $89.90 \%$ \\
\hline $\begin{array}{l}\text { Non-built } \\
\text { up land }\end{array}$ & 25 & 268 & 293 & $91.46 \%$ \\
\hline Total & 310 & 300 & 610 & \\
\hline $\begin{array}{l}\text { Producer's } \\
\text { accuracy }\end{array}$ & $91.93 \%$ & $89.33 \%$ & & \\
\hline $\begin{array}{l}\text { Overall } \\
\text { accuracy }\end{array}$ & $90.65 \%$ & & kappa & 0.812 \\
\hline
\end{tabular}

The total areal extent of Kozhikode Urban Agglomeration is $1803 \mathrm{~km}^{2}$. After converting the raster to polygon, the areal extent of built-up classes for different years is obtained. For the year 1991, the built-up areal extent of KUA was about 324.54 $\mathrm{km}^{2}$, which was $18 \%$ of its total land area. In the year 2000 , the built-up areal extent increased to $522.87 \mathrm{~km}^{2}(29 \%$ of the total geographical area of KMA). When it reaches 2018, the built-up areas increased to an areal extent of $829.38 \mathrm{~km}^{2}(46 \%$ of KMA's total area). Figure 5 shows the built-up area change for the years 1991, 2000 and 2018.

\section{Built-up Area Change of KUA}

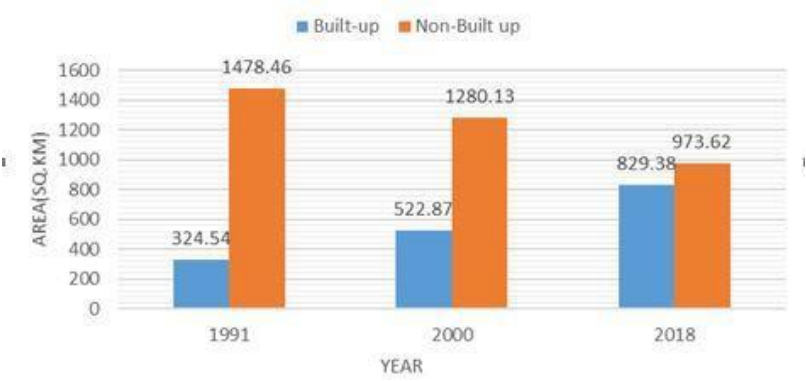

Figure 5: Change in the areal extent of built-up and non-builtup classes for 1991, 2000 and 2018.

From the above graph, it is clear that there is an alarming increase in the built-up area from 1991 to 2018, which indirectly highlights that there is severe urban sprawl/urban growth in the study area. The method of extracting built-up features from various indices is found to be very effective and efficient compared to traditional methods of built-up land extraction like supervised image classification which is tedious and time-consuming.

\subsubsection{Urban Sprawl Analysis Using Shannon's Entropy}

Rudolph Clausius, in 1867, proposed the concept of entropy from the second law of Thermodynamics. (Claudius, 1867). In the year 1948, Shannon has developed the concept of entropy as a measure of randomness and disorganization. In view of the complexities of urban growth, sprawl and urban evolution, entropy value must remain within the range set by the minimum value below which the system becomes vulnerable and unstable, and the maximum value over which the system becomes unsustainable. (Cabral, 2013). The integration of GIS and remote sensing technologies allows to effectively apply the entropy principle in the calculation of urban sprawl. Shannon's entropy measure is one of the most commonly used urban sprawl indexes to describe the degree of dispersion or spatial concentration of a specific variable in a particular area. (Bhatta(2009), Li (2004)).The formula of Shannon's entropy ( $\left.H_{n}\right)$ is

$H_{n}=-\sum_{i=1}^{n} P_{i} \log _{e}\left(P_{i}\right)$

Where $P_{\hat{i}}$ denotes probability of a phenomenon (variable) occurring in the $\mathrm{i}^{\text {th }}$ zone $\left(P_{i}=\frac{x_{i}}{\sum x_{i}}\right.$, where $x_{i}$ is the observed value of the variable in the $i^{\text {th }}$ zone), and $n$ denotes the total number of zones/ grids. The range of Shannon's entropy value varies from 0 to $\operatorname{loge}(\mathrm{n})$. Values closer to zero means that builtup features are extremely compact in distribution, while values closer to loge(n), indicates the scattered distribution of built-up areas. Higher entropy values highlight sprawl occurrence. The threshold value to categorize sprawl and non-sprawl is taken as the mid-way mark of loge(n). If a city crosses its threshold entropy value, it is said to be a sprawling city. The difference in entropy between two time intervals $\mathrm{t} 1$ and $\mathrm{t} 2$ can be used to show the magnitude of urban sprawl transition.

Here, the study area is divided into 17 grid zones, each of size $15 \mathrm{~km} \times 15 \mathrm{~km}$. Considering each grid as a distinct spatial entity, Shannon's entropy has been calculated for all the 17 grid zones. The total number of zones in KMA is thus, $n=17$ and the upper limit of entropy value is loge $(n)=2.833$. Figure 6 shows Shannon's entropy grid map of 1991 .

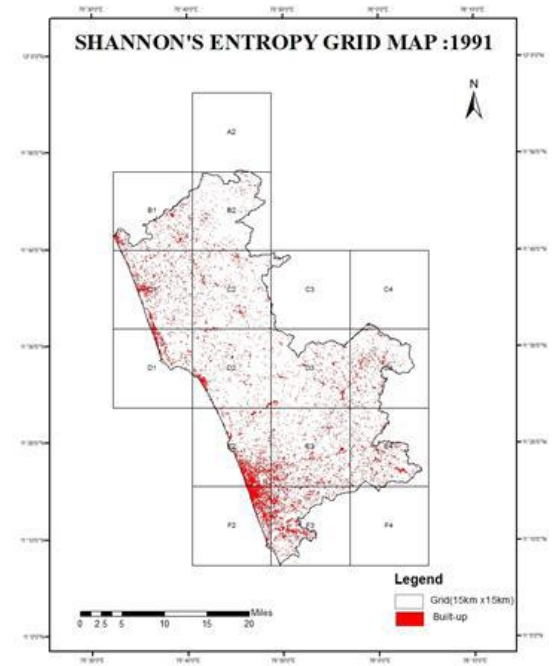

Figure 6: Shannon's Entropy Grid Map of Study Area 
For the Kozhikode Urban Agglomeration, the value of Shannon's entropy has been calculated from the built-up areas for all the 17 zones over the years 1991, 2000, and 2018. The results are summarized in Table 3 and Table 4.

Table 3: Shannon's entropy calculation for 17 grids over the years 1991, 2000, and 2018 .

\begin{tabular}{|c|c|c|c|c|c|c|c|}
\hline & Year & 1991 & 2000 & 2018 & 1991 & 2000 & 2018 \\
\hline & & \multicolumn{3}{|c|}{ Built-up Area (sq.km) } & \multicolumn{3}{|c|}{$-\boldsymbol{P}_{i} \log _{\boldsymbol{e}}\left(\boldsymbol{P}_{i}\right)$} \\
\hline & A2 & 0 & 0.15 & 0.95 & 0 & 0.000782 & 0.003977302 \\
\hline & B1 & 12.7 & 28.64 & 44.78 & 0.034906371 & 0.065801 & 0.091781506 \\
\hline & B2 & 22.47 & 38.33 & 57.32 & 0.054648662 & 0.081868 & 0.109634677 \\
\hline & C1 & 21.99 & 43.87 & 53.76 & 0.053744626 & 0.090416 & 0.104737406 \\
\hline & C2 & 43.54 & 55.98 & 61.98 & 0.089918121 & 0.107806 & 0.115860849 \\
\hline G & C3 & 0 & 0.09 & 8.55 & 0 & 0.000494 & 0.025376267 \\
\hline $\mathrm{r}$ & C4 & 0 & 0.65 & 16.37 & 0 & 0.002858 & 0.042688718 \\
\hline $\mathrm{i}$ & D1 & 10.579 & 29.76 & 59.17 & 0.030148896 & 0.067741 & 0.11213068 \\
\hline \multirow[t]{2}{*}{ d } & $\mathrm{D} 2$ & 44.87 & 58.69 & 79.93 & 0.091916003 & 0.111486 & 0.138139963 \\
\hline & D3 & 6.7 & 20.55 & 43.82 & 0.020791552 & 0.050997 & 0.090340578 \\
\hline $\mathbf{N}$ & D4 & 5.5 & 12.9 & 31.96 & 0.017669731 & 0.035344 & 0.071484081 \\
\hline u & E2 & 37.33 & 51.75 & 78.9 & 0.080279375 & 0.101915 & 0.136927427 \\
\hline $\mathrm{m}$ & E3 & 43.001 & 51.95 & 78.88 & 0.089102075 & 0.102198 & 0.136903809 \\
\hline b & E4 & 27.36 & 38.7 & 47.89 & 0.063553579 & 0.082452 & 0.09637233 \\
\hline e & F2 & 19.73 & 46.87 & 82.6 & 0.049407804 & 0.094879 & 0.141249094 \\
\hline \multirow[t]{2}{*}{$r$} & $F 3$ & 28.77 & 43.86 & 78.13 & 0.066026975 & 0.090401 & 0.136016102 \\
\hline & F4 & 0 & 0.13 & 4.39 & 0 & 0.000688 & 0.014652515 \\
\hline \multicolumn{5}{|c|}{ Shannon's Entropy, $\mathrm{Hn}$} & 0.742113771 & 1.088126 & 1.568273306 \\
\hline
\end{tabular}

Table 4: Shannon's entropy with the magnitude of urban sprawl change $\left(\Delta H_{n}\right)$ for the years 1991,2000 and 2018

\begin{tabular}{|l|l|l|l|}
\hline SI.No & Year & $\begin{array}{l}\text { Shannon's } \\
\text { Entropy }\end{array}$ & $\Delta \boldsymbol{H}_{\boldsymbol{n}}$ \\
\hline 1 & 1991 & 0.74 & - \\
\hline 2 & 2000 & 1.09 & 0.35 \\
\hline 3 & 2018 & 1.57 & 0.48 \\
\hline \multicolumn{3}{|c|}{$\log _{\mathrm{e}}(\mathrm{n})=2.833$} \\
\hline
\end{tabular}

Figure 7 shows the graphical variation of Shannon's entropy values for the years 1991, 2000, and 2018. We can see an increasing trend in the value of Shannon's entropy values from 1991 to 2000 and to 2018. The increase in the value of Shannon's entropy indicates an increase in the dispersion of built-up areas, which in turn is an indication of the occurrence of the phenomenon of urban sprawl. As the values get more and more closer to the upper entropy limit (2.833), there is more and more dispersion of built-up areas in the region. The difference in entropy between the years 1991 and 2000 is 0.35 , and 2000 and 2018 are 0.48 . Here also, we can see a tremendous increase in urban sprawl as the years pass.

\section{Shannon's Entropy Change over the years}

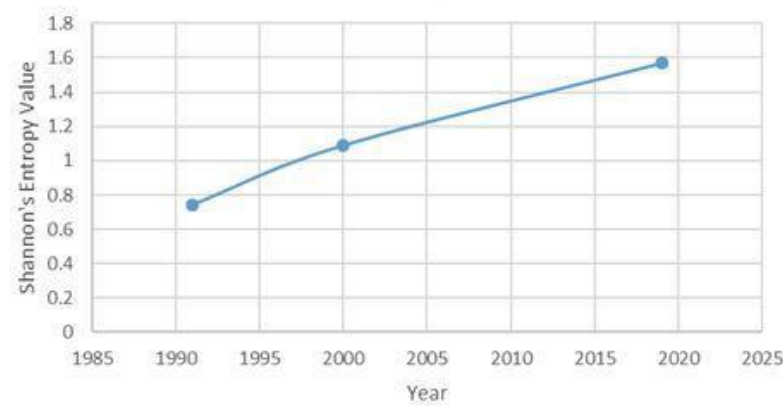

Figure 7 : Graphical Variation of Shannon's Entropy Values Over the Years
The maximum entropy value is 2.833 , whereas the threshold value is identified as 1.42 which is exactly the half-way mark of loge(n). The value of entropy is less than the threshold value of 1.42 in the years 1991 and 2000. But in the year 2018, the entropy value exceeds the threshold value which in turn highlights the fact that the city is sprawling. From this figure, we can easily conclude that the city started its tendency to sprawl from the year 2012 onwards.

\section{CONCLUSION}

The issue of urban sprawl is a matter of concern in many countries across the world, especially in developing countries. If it is left unchecked, the phenomenon of uncontrolled urban sprawl will ultimately result in damaging impacts on urban sustainability. To evaluate and monitor the changes in urban settings, continuous spatial and temporal monitoring of our urban environment is a must. Together with its persistent and synoptic coverage, the multispectral capabilities of satellite remote sensing make it a versatile instrument for mapping and monitoring the changes in the urban core and urban planning applications. This will help to reduce unplanned urban expansion and thus helps in the preservation of sustainability of our urban environments. Adequate spatial inputs which portray the urban sprawl phenomenon can be obtained cost-effectively and efficiently using integrated GIS and remote sensing technologies. The dynamics of built-up area change over the years give noteworthy information about the nature, extent and development of urban sprawl.

In this study, the built-up area is considered as an indicator of urban sprawl. Built-up features of the study area for the years 1991, 2000 and 2018 were obtained from an automated thematic index-based index known as Index derived built-up index (IDBI). IDBI is derived from three thematic indices viz, Normalized Difference Built-up Index (NDBI), Modified Normalized Difference Water Index and Soil Adjusted Vegetation Index (SAVI). Built-up land features can be rapidly extracted, whereas soil, water, and vegetation noises, etc can be effectively suppressed using IDBI. The accuracy assessment showed that the overall accuracy is $90.65 \%$, with a kappa coefficient of 0.812 . A commonly used urban sprawl metric called Shannon's entropy is used for the measurement and quantification of the phenomenon of urban sprawl in the study area. The spatial concentration or degree of dispersion in a particular area can be easily tracked using Shannon's entropy coupled with remote sensing and GIS. The results of IDBI and Shannon's entropy analysis highlight the fact that there occurs an alarming increase in the built-up areal extent from 1991 to 2018. The city started its tendency to sprawl from the year 2012 onwards. The urban planning authorities can make use of these techniques of built-up area extraction and urban sprawl analysis for effective city planning and sprawl control. There is a need to create innovative approaches and further refine current methods and techniques in order to take complete benefit of the variety of remote sensing data within the urban setting

\section{REFERENCES}

1. Barnes, K.B., Morgan JM, Roberge MC, and Lowe S. (2001). "Sprawl development: its patterns, consequences, and measurement," Towson University, Towson, 1-24

2. Bhatta, B. (2009) Analysis of urban growth pattern using remote sensing and GIS: a case study of Kolkata, India. International Journal of Remote Sensing, 30(18) 4733-4746. 
3. Bhatta B. (2010), Analysis of Urban Growth and Sprawl from Remote Sensing Data, Springer, Cham

4. Bhatta, B. (2012). Urban Growth Analysis and Remote Sensing; A Case Study of Kolkata, India 1980-2010, ISSN 2211-4173, Canada: Springer.

5. Pedro Cabral 1, *, Gabriela Augusto 1, Mussie Tewolde 2 and Yikalo Araya 3, Entropy 2013, 15, 5223-5236; DOI:10.3390/e15125223, Review Entropy in Urban Systems 6. Claudius, R. The Mechanical Theory of Heat: With its Applications to the Steam-Engine and the Physical Properties of Bodies; J. Van Voorst: London, UK, 1867; p. 376

7. DiLorenzo, W., 2000. The myth of suburban sprawl. USA Today (May) 128: 54-6.

8. Ewing, R., Pendall R. and D. Chen., (2002): Sprawl Scores for 83 Metropolitan Regions. Washington D. C: Smart Growth America

8. Freilich, R. (1999). From sprawl to smart growth: successful legal, planning, and environmental systems. Chicago: American Bar Association.

9. Frenkel, M. A. (2005). "Measuring Urban Sprawl; How can we deal with it?", ERSA conference papers from the European Regional Science Association

10. Galster, G., Hanson, R., Ratcliffe, M. R., Wolman, H. Coleman, S. \& Freihage, J., (2001): Wrestling sprawl to the ground: defining and measuring an elusive concept, Housing Policy Debate, vol. 12, no 4, pp.681-717

11. Gordon, P. and Richardson, H. (1997) Are Compact Cities a Desirable Planning Goal Journal of the American Planning Association, 63, 95-106.

12. Hiller, B.T., Melotte, B. J., Hiller, S. M.2013. Uncontrolled Sprawl or Managed Growth? An Australian Case Study, Leadership and Management in Engineering

13. Li, X., \& Yeh, A. G. O. (2004). Analyzing spatial restructuring of land use patterns in a fast growing region remote sensing and GIS. Landscape and Urban Planning, 69, 335-354).

14. McFeeters, S.K. (1996), The use of normalized difference water index in the delineation of open water features, International Journal of Remote Sensing, pp 1425-1432

15. NASA (2001) Satellite maps provide better urban sprawl insight. NASA, USA

16. Nelson, A. C., Duncan, J., Mullen, C., and Bishop, K., 1995, Growth management: Principles and practices, APA Planners Press, Chicago

17. Polidoro, Mauricio, Lollo, Jose A., Barros, Mirian V.F. (2011). "Environmental Impact of Urban Sprawl in Londrina, Parana, Brazil," Journal of Urban and Environmental Engineering, S. 5(1), s. 73-83.

18. Prakash, A., Gupta, R. P. (1998), Land-use mapping and change detection in a coal mining area-a case study in the Jharia coalfield, India, International Journal of Remote Sensing, 19(3), pp. 391-410

19. Ray, T.W. (2006)., Vegetation in Remote Sensing FAQ's. In ER Mapper Applications, pp 85-97, (Perth, Australia, ER Mapper Ltd)

20. Rawashdeh, S. A., Saleh, B. (2006), Satellite monitoring of urban spatial growth in Amman Area, Jordan, Journal of Urban Planning and Development, 132(4), pp. 211-216

21. Song, Y, G.-J. Knaap. (2004). "Measuring Urban Form-Is Portland Winning the War on Sprawl?", Journal of the American Planning Association, 70, 210-225

22. Sudhira, H.S., Ramachandra, T.V., Jagadish, K.S 2004, « Urban Sprawl: metrics, dynamics, and modeling using GIS, » International Journal of Applied Earth Observation and Geoinformation 5: 29-39.7)
23. UN's World Urbanization Prospects (2018), United Nations Department of Economic and Social Affairs: World Urbanization Prospects: 2018, The 2018 Revision, UNDESA. 24.Web-1:

https://www.un.org/en/ecosoc/integration/pdf/fact_sheet.pdf). 25. Web-2: (USGS) portal: https://earthexplorer.usgs.gov/ 26. Wilson, Emily H., Hurd, James D., Civco, Daniel, Arnold, Chester L. (2003). "Development of a Geospatial Model to Quantify, Describe and Map Urban Growth," Remote Sensing of Environment, S. 86(3), s. 275-285.

27. Xu, H. (2008), Anew index for delineating built-up land features in satellite imagery, International journal of remote sensing, Vol.29, No.14, pp 4269-4276

28. Zha, Y., Gao, J., Ni, S. (2003)., Use of normalized difference built-up index in automatically mapping urban areas from TM images, International Journal of Remote Sensing, pp 583-594 